\title{
Contributions of a global network of tree diversity experiments to sustainable forest plantations
}

\author{
Kris Verheyen, Margot Vanhellemont, Harald Auge, Lander Baeten, Christopher Baraloto, \\ Nadia Barsoum, Simon Bilodeau-Gauthier, Helge Bruelheide, Bastien Castagneyrol, \\ Douglas Godbold, Josephine Haase, Andy Hector, Hervé Jactel, Julia Koricheva, Michel Loreau, \\ Simone Mereu, Christian Messier, Bart Muys, Philippe Nolet, Alain Paquette, John Parker, \\ Mike Perring, Quentin Ponette, Catherine Potvin, Peter Reich, Andy Smith, Martin Weih, \\ Michael Scherer-Lorenzen
}

Received: 31 January 2015/Revised: 16 June 2015/Accepted: 27 June 2015/Published online: 12 August 2015

\begin{abstract}
The area of forest plantations is increasing worldwide helping to meet timber demand and protect natural forests. However, with global change, monospecific plantations are increasingly vulnerable to abiotic and biotic disturbances. As an adaption measure we need to move to plantations that are more diverse in genotypes, species, and structure, with a design underpinned by science. TreeDivNet, a global network of tree diversity experiments, responds to this need by assessing the advantages and disadvantages of mixed species plantations. The network currently consists of 18 experiments, distributed over 36 sites and five ecoregions. With plantations $1-15$ years old, TreeDivNet can already provide relevant data for forest policy and management. In this paper, we highlight some early results on the carbon sequestration and pest resistance potential of more diverse plantations. Finally, suggestions are made for new, innovative experiments in understudied regions to complement the existing network.
\end{abstract}

Keywords Biodiversity experiments .

Functional biodiversity research - Plantation forest .

Sustainable forest management $\cdot$ Ecological restoration

\section{A GLOBAL CALL FOR SUSTAINABLE FOREST PLANTATIONS}

Although the global forest area declined by ca. 13 million ha per year between 2000 and 2010, the forest plantation area actually increased annually by ca. 5 million ha in the same time period, representing ca. $7 \%$, i.e., 264 million ha, of the global forest area in 2010 (FAO 2010). Afforestation rates may increase further due to incentives for carbon sequestration and the global pledge to protect the remaining natural forests of the world against degradation, e.g., as part of REDD + . Forest plantations already provide up to $33 \%$ of the total industrial roundwood volume harvested annually in the world, and are projected to make up as much as $50 \%$ of the global industrial roundwood production by 2040 (Kanninen 2010). Beyond wood production, plantations also provide a range of other ecosystem services, including carbon sequestration and water retention (Pawson et al. 2013). Moreover, when incorporated into integrated landscape management, plantations can play a large role in achieving biodiversity conservation objectives by offsetting the need to extract resources from natural forests (Paquette and Messier 2010).

Currently, plantation forests are almost exclusively planted as monocultures (Nichols et al. 2006, Box 1). Yet, several reviews published recently provide evidence, from both natural forests and plantations that biomass production and the delivery of other ecosystem services can improve with tree diversity (Nadrowski et al. 2010; Scherer-Lorenzen 2014). Furthermore, global change may increase disturbance frequencies and intensities in both natural forest (Woods et al. 2005) and plantations (Pawson et al. 2013), significantly affecting wood supply chains with severe economic consequences (Hanewinkel et al. 2012). Forest plantations that are diverse in genotypes, species, structure, and function, should be better able to adapt to changing environmental conditions than monocultures (van Hensbergen 2006; Bauhus et al. 2010). This calls for the development of novel, more diversified forest plantations that can improve plantations' stability, productivity, and delivery of ecosystem services. Since plantations are often established near human settlements, they are the primary window through which society looks at forest management. Changing the way we manage plantations and setting objectives for them can therefore have profound and rapid impacts on the social acceptance of 
forestry (Paquette and Messier 2013). It has been noted, however, that foresters currently resist establishing mixed plantations, in large parts because of the perception that mixing genotypes and species reduces yield and complicates forest management operations (Carnol et al. 2014).

TreeDivNet, a new global network of tree diversity experiments, responds to the need for a solid, sciencebased framework for documenting and understanding the benefits and drawbacks of mixed plantations. In this paper, we explain the need for new afforestation trials and present the TreeDivNet network of experimental plantations. We show some early results from the network and formulate suggestions for additional experimental plantations that may cover existing research gaps.

\section{BOX 1}

Multi-species tree plantations are still relatively rare worldwide, but is this topic important within the forest research communities and is there an increasing interest in the last 10 years? We investigated these questions using the software WORDSTAT 6.0 (Péladeau 2003) by comparing the percentage of abstracts containing the word "plantation" that also contained the words "species mixture, mixed system, mixed plantation, mixed-species plantation or multispecies plantation" between the proceedings of the IUFRO World Congresses ${ }^{1}$ of 2005 and 2014. In the proceedings of 2014, we found 2426 abstracts of which 267 used the term "plantation". Of these 267 abstracts, 20 (or $7.5 \%$ ) also used at least one of the terms referring to mixed plantation mentioned above. In the proceedings of 2005, we found 1454 abstracts of which 238 used the term "plantation". Of these 238 abstracts, only 1 (or $0.4 \%$ ) used at least one of the terms referring to mixed plantation. This clearly shows that the interest in multi-species tree plantations is increasing, which bodes well for the future of such plantations worldwide.

\section{THE NEED FOR A TWENTY-FIRST CENTURY GENERATION OF FOREST PLANTATION TRIALS}

In the eighteenth and nineteenth century, foresters such as von Carlowitz, Hartig and Cotta developed the concepts of sustainable forest management as a response to the increasing overexploitation of European forests (Morgenstern 2007). To base these concepts upon science, the first

\footnotetext{
${ }^{1}$ IUFRO is the International Union of Forest Research Organizations and organizes its world congress every 4 or 5 years (www.iufro.org).
}

long-term silvicultural trials were established to identify the most productive species and provenances to plant in novel forests. The trials were definitely a success for the development of production-oriented management; largescale forest plantations were established with fast-growing tree species. The trials were often designed as common garden experiments comparing the growth and performance of different species and provenances at one site, i.e., under similar environmental conditions. Despite the lively debate about the advantages and disadvantages of pure versus mixed forests (even in that early era), most of the trials consisted of monocultures or, less frequently, twospecies mixtures (Scherer-Lorenzen 2014). Presently, 300 years after von Carlowitźs proposition of sustainability and given recent advances in biodiversity science (e.g., Cardinale et al. 2012), we need to know which mixtures provide higher levels of biomass production and of other ecosystem services and how environmental conditions affect the relationship between tree diversity and forest functioning, both in space and time.

To address these issues, several scientific approaches are available. Given the long lifespan and size of trees, simulation models that predict ecosystem service output along a range of tree diversities and environmental conditions are an obvious approach. However, such models need parameterization, which is an enormous challenge given how poorly we understand biotic interactions among species. Parameters can be estimated based on experiments or observational studies, but both the types and ranges of tree diversities we seek to study are not always present. Still, highly interesting and relevant work has been accomplished with simulation tools (e.g., Morin et al. 2011). Observational studies are invaluable for providing realworld reference data (Baeten et al. 2013), but also have many drawbacks because tree species composition strongly depends on environmental factors or management. Experiments avoid these issues, but there are still relatively few experiments with replicated stands of mixed species (Scherer-Lorenzen 2014), and many of these use only a small number of (nevertheless commercially important) tree species.

\section{TREEDIVNET AND EXAMPLES OF ITS POTENTIAL TO CONTRIBUTE TO SUSTAINABLE FOREST PLANTATIONS}

In response to the need for in-depth knowledge of the functioning of mixed plantations and the services they provide, tree diversity experiments have been planted worldwide over the past 15 years. These experiments have now been integrated within the global network TreeDivNet (www.treedivnet.ugent.be). The unifying characteristic of 
TreeDivNet experiments is that tree species are grown in both monoculture and mixtures, and that tree diversity levels are replicated in a randomized design, allowing for the effects of diversity to be tested. Tree diversity experiments can yield reliable estimates of ecosystem functioning as the experimental design controls the levels and range of tree diversity and allows accounting for potentially confounding factors due to site conditions and local environmental gradients. In addition, long-term monitoring of the performance of individual trees and multiple ecosystem processes in experiments will provide a rich record of the development of the forest ecosystem and its overall functioning (see for example Potvin and Gotelli 2008). This will lead to a deeper understanding of the influence of the diversity, composition and structure of a forest on its functioning, and a more complete picture of the relationships between productivity and other ecosystem functions and services. Long-term monitoring will also allow us to better understand how forest diversity, structure, and composition influence forest stability. We will then be able to plant and manage forests in a way that increases their resistance and resilience to, e.g., predicted changes in climate. Different aspects of tree diversity, i.e., species richness, genetic diversity, structural, and functional diversity, will be used as tools to face the key challenges of modern sustainable afforestation.

At present, TreeDivNet consists of 18 experiments, located at 36 sites and in five ecoregions (Fig. 1; Table 1). More than 1000000 trees have been planted in the experiments on a total surface area of ca. 800 ha, which makes TreeDivNet one of the largest research infrastructures in ecology worldwide. The oldest experiment (Satakunta, Finland) was planted in 1999. The experiments included in TreeDivNet manipulate woody plant diversity - in terms of species richness (taxonomic diversity), evenness, composition, genetic, and functional diversity — over wide diversity gradients and are designed to allow separation of diversity and identity effects (see Fig. 2 for an example, and Bruelheide et al. 2014). The tree species in the TreeDivNet experiments are both widely planted commercial species, but also many less frequently used species. One important additional component is the inclusion of tree provenances from different regions (e.g., BiodiversiTREE, US; FORBIO, Belgium; and Climate Match, UK), providing a valuable opportunity to test whether assisted migration enhances the services provided by diverse plantations in the face of climate change (Pedlar et al. 2012).

TreeDivNet functions according to the guidelines for globally distributed experiments (cf. Borer et al. 2014). At present, the network has no central funding. Participation is entirely voluntary, but has clear benefits for the participants. TreeDivNet offers unique opportunities for multidisciplinary and multifunctional research on the relationship between tree diversity and ecosystem functioning in major forest types around the world and enables synthesis studies across the globe. Thus, TreeDivNet contributes to the lively field of functional biodiversity research, which has delivered a wealth of knowledge about the biotic control of ecosystem functioning over the last two decades. However, most of this knowledge was gained in smaller-stature, shorter-lived vegetation such as grasslands; forests came into the focus of this research field only recently. Despite the young age of most experiments, TreeDivNet can already provide results relevant for policy and management, as illustrated in the following two examples.

\section{Species identity, plot diversity, and mixture composition as determinants of aboveground carbon sequestration}

The possibility of using afforestation to create carbon sinks while taking biodiversity concerns into account provides a good example of the potential contributions of experimental tree plantations within TreeDivNet. Sequestering both above and belowground carbon has been recognized in the context of the Clean Development Mechanism of the Kyoto protocol (Thomas et al. 2010), and has gained momentum with the development of an International mechanism for reducing emissions from deforestation and forest degradation known as REDD+ (Cerbu et al. 2011). However, the choice of provenance/genotype and species, each with different carbon sequestration time profiles, and the positive or negative effects of mixtures for maximizing carbon sequestration rates in forest plantations at different sites across the globe are still open to debate.

According to FAO's Global Planted Forest Assessment database (FAO 2006), the total number of species used in plantations ranges from four in Finland to twenty in China, France, India, and Ukraine. Yet, studies in TreeDivNet experimental plantations suggest that the carbon sequestration rates of tree species that are rarely planted in forestry may be higher than for species that are traditionally planted for wood production. In Sardinilla, Panama, for instance, only one of the four species with the highest carbon stocks after 10 years of growth, Dalbergia retusa, is currently used as a timber-producing species (Fig. 3a). In BEF-China, Choerospondias axillaris, Nyssa sinensis, Triadica cochinchinensis, Melia azedarach, and Schima superba, which are not currently used for commercial timber, were found to sequester more carbon 2 years after planting than the commercially planted timber species Cunninghamia lanceolata or Pinus massioniana. Early observations thus support the presence of species identity effects, which highlights the importance of increasing the number of species used in plantation projects. 


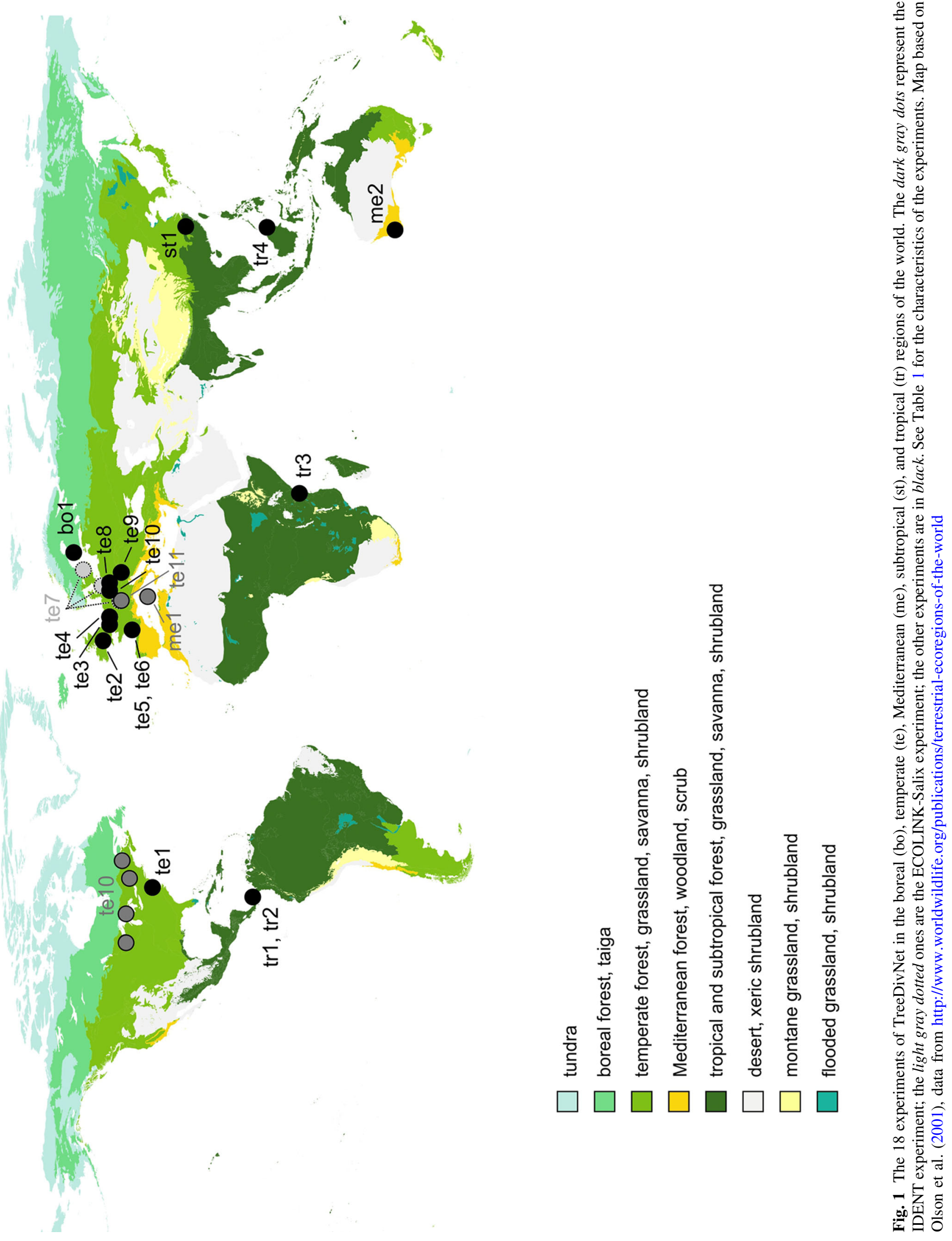




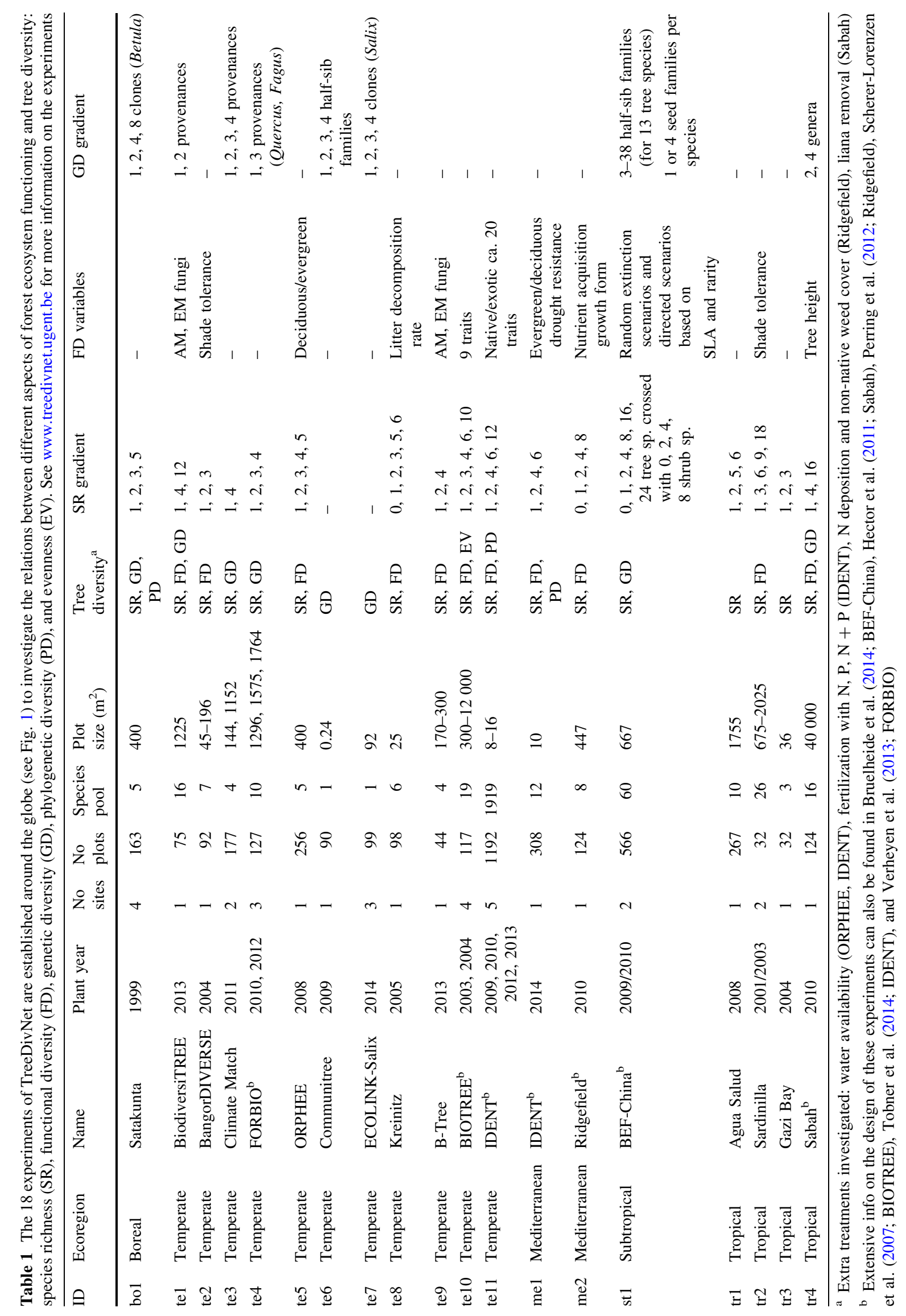




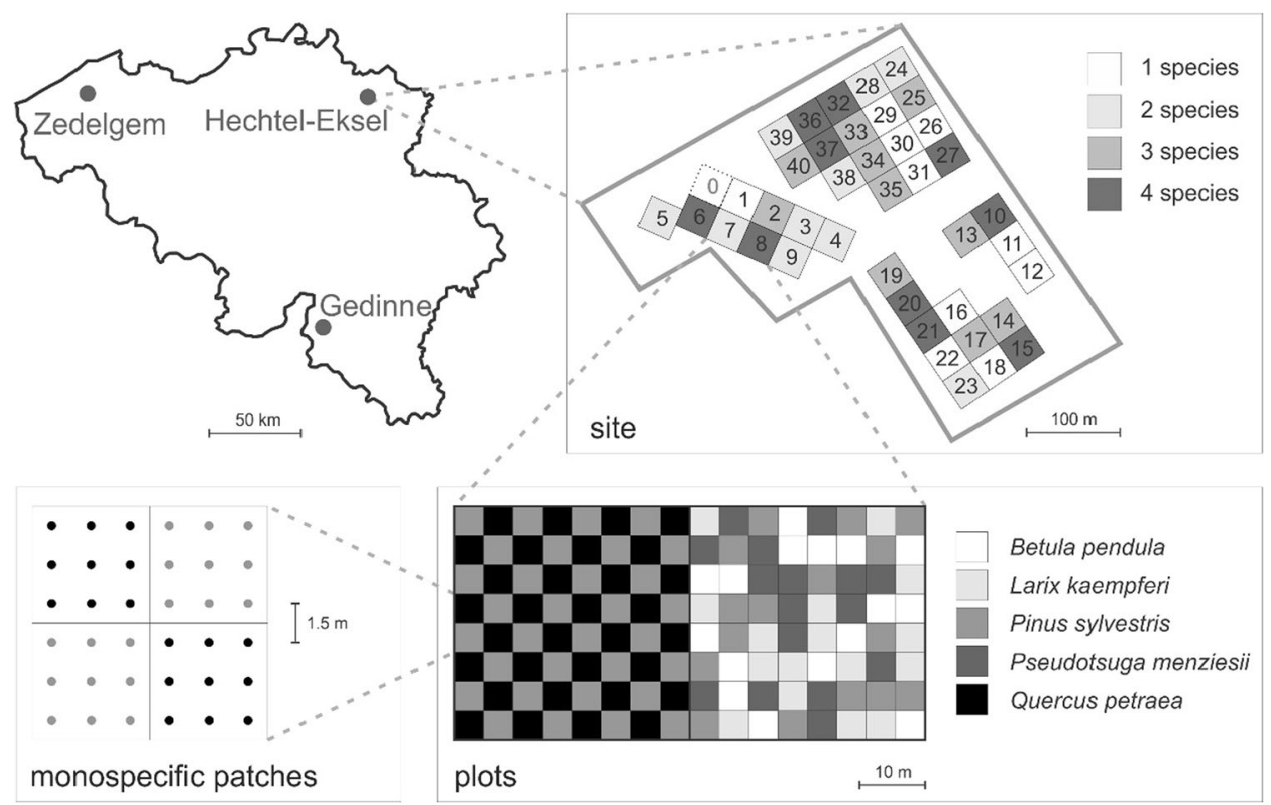

Fig. 2 Example of the design of one of the TreeDivNet experiments. The FORBIO experiment was established at three sites in Belgium. The tree species diversity per plot ranges from one to four species. The within-plot design is shown for a two-species and a four-species plot. The trees were planted on a $1.5 \mathrm{~m} \times 1.5 \mathrm{~m}$ grid, in small monospecific patches of $3 \times 3$ trees. These patches are arranged in a checkerboard pattern in the two-species mixtures and randomly attributed to the species in the three- and four-species mixtures (see Verheyen et al. 2013 for more details)

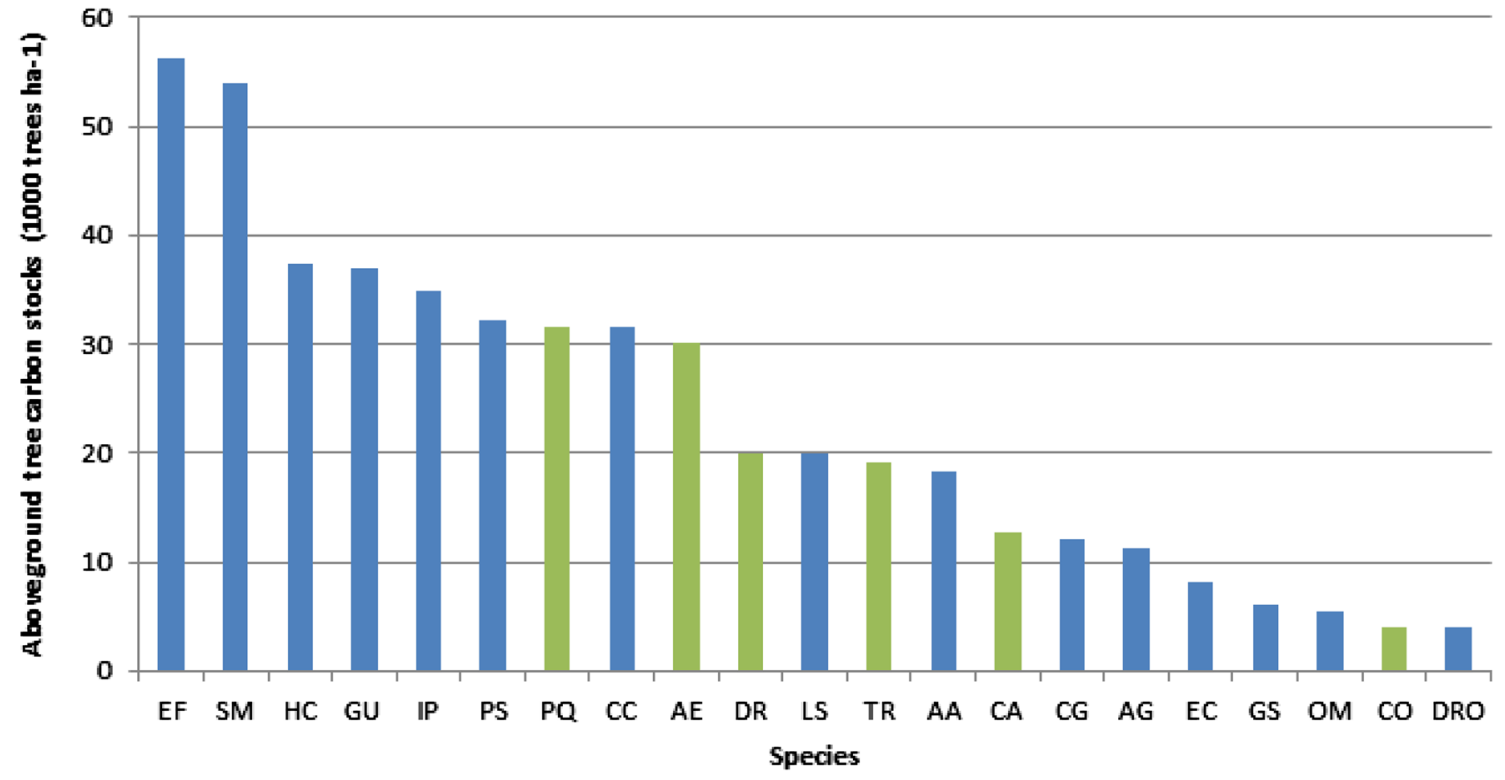

Fig. 3 Aboveground biomass $\left(\mathrm{Mg} \mathrm{C} \mathrm{ha}^{-1}\right)$ after 10 years of growth in the Sardinilla experiment (Panama). The common timber species are indicated in green in the figure and underlined here. Species abbreviations are the first letter of the genus and species name: Albizia adinocephala, Anacardium excelsum, Astronium graveolens, Cordia alliodora, Calycophyllum candidissimum, Colubrina glandulosa, Cedrela odorata, Dalbergia retusa, Diphysa robinioides (DRO), Enterolobium cyclocarpum, Erythrina fusca, Gliricidia sepium, Guazuma ulmifolia, Hura crepitans, Inga punctata, Luehea seemannii, Ormosia macrocalyx, Pachira quinata, Pseudosamanea guachapele, Spondias mombin, Tabebuia rosea. The biomass was calculated using the equation of Chave et al. (2005) equation for tropical moist forest, and mean tree biomass per species was scaled up to 1 ha assuming 1000 trees per plot. Estimations were done for the species represented in the Sardinilla planted forest by at least five individuals 


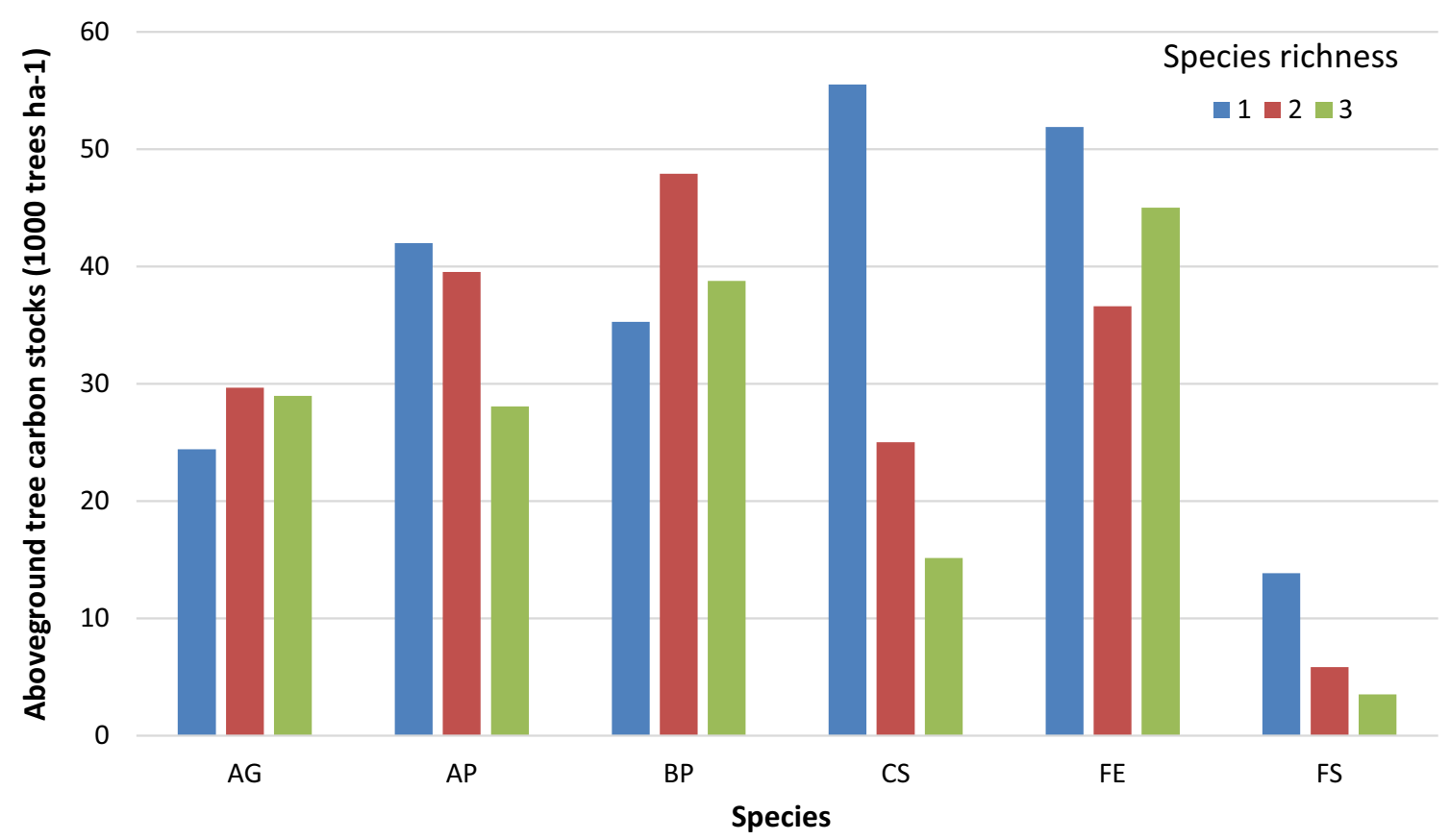

Fig. 4 Aboveground carbon ( $\mathrm{Mg} \mathrm{C}^{-1}$ ) after 9 years of growth at the BangorDIVERSE experiment (UK). Species abbreviations are the first letter of the genus and species name: Alnus glutinosa, Acer pseudoplatanus, Betula pendula, Castanea sativa, Fraxinus excelsior, Fagus sylvatica. The biomass was calculated using general European temperate forest equations from Ziania et al. (2005) and site-specific equations from Smith et al. (2013). Mean tree biomass per species was scaled up to one hectare assuming 1000 trees per plot. Biomass estimations were based on the average species diameter of each replicate plot $(n=3)$

Nevertheless, widespread application of these new species is probably contingent on their potential use as timber species.

TreeDivNet experiments also allow comparing the provisioning of ecosystem services from mixed as opposed to monoculture plantations. A recent meta-analysis, using data from a TreeDivNet experiment and elsewhere, indicates that woody mixtures sequester at least as much aboveground carbon as the most productive monocultures in any given location (Hulvey et al. 2013). This suggests that plantations could use mixtures of multiple species selected outside of traditional forestry practice to maximize aboveground carbon storage, if the latter would be the primary interest. Furthermore, early TreeDivNet results indicate that the performance of high carbon sequestering species might be contingent upon the diversity level of the plot in which they are growing. In BangorDIVERSE, UK, Alnus glutinosa and Betula pendula were more efficient at storing carbon after 9 years than some traditional timberproducing species, with A. glutinosa performing better in mixture than in monoculture (Fig. 4). In Sardinilla, mixtures established with three and six species overyielded compared with monocultures and this effect of diversity increased with time over 10 years (Sapijanskas et al. 2013). However, variability among plots with the same species richness level also suggests that certain combinations of species are apparently able to sequester more carbon than others.

We propose that, in order to more easily identify species and mixtures that sequester high levels of carbon, relationships between carbon sequestration rates and common life history traits could be useful. Early data collected at TreeDivNet experiments suggest that these relationships may be site specific, as has been found in natural forests (Stegen et al. 2009).

\section{Which mixtures optimize insect pest control in young tree plantations?}

Although often less spectacular than abiotic disturbances such as storms or fires, biotic damage can dramatically alter the functioning of forest ecosystems and reduce their productivity. For instance, every year, on average 15-20\% of the trees in European forests are affected by pest and pathogen damage, resulting in increased tree mortality or reduced tree growth. Climate change with increasing temperatures and more frequent drought events is expected to aggravate forest pest damage through increased pest proliferation or reduced plant defense (Jactel et al. 2012). It is therefore critical to better understand the significance of forest diversity for the forest's resistance to pest insects and its resilience to their outbreaks. 
Meta-analyses have shown that, overall, mixed forests are less prone to pest insect damage than monocultures (Jactel and Brockerhoff 2007), supporting the associational resistance hypothesis. This hypothesis states that focal trees surrounded by heterospecific neighbors are less likely to be found and affected by insect herbivores. However, these reviews have several limitations: (1) they focused on the effects of single pest species, whereas the entire community of insect herbivores interacts with the trees; (2) the long-term effects of insect herbivory have not been studied; and (3) the ecological mechanisms underlying associational resistance could not be investigated in detail.

By contrast, the design of the TreeDivNet experiments makes it possible to address these issues. Indeed, early results on diversity-herbivore resistance relationships from BIOTREE (Germany), FORBIO (Belgium), Satakunta (Finland), and ORPHEE (France) indicate that the identity of the focal (Fig. 5) and associated tree species appeared to be more important than plot species richness per se in explaining the effects of tree diversity on insect herbivory damage. Interestingly, there were more cases found for associational susceptibility, which might be due to the young age of the experiments and/or the assessment of all insect damage rather than focus on few pests, as done in other studies. Insect damage is now a staple protocol in most TreeDivNet experiments and so more results over a greater span of conditions will be available soon.

A recent meta-analysis, which included data from several TreeDivNet experiments, has shown that both phylogenetic relatedness of tree species in mixtures and insect herbivore feeding specialization are important predictors of forest diversity effects on insect pests (Castagneyrol et al. 2014). The degree of dilution of a focal tree species among non-host trees was also important in associational resistance (Castagneyrol et al. 2013). Moreover, reduced hosttree apparency recently emerged as a main driver of resistance in mixed stands as neighboring heterospecific trees can disrupt host-finding behavior in insect herbivores (Castagneyrol et al. 2013). Finally, mixed forests can provide natural enemies with more feeding resources or microhabitats and thus enhance the biological control of pest insects (Riihimaki et al. 2005).

These preliminary findings provide a basis for several recommendations for the design of mixed species plantations that can be more resistant to insect pests: (1) mixing more functionally and phylogenetically dissimilar tree

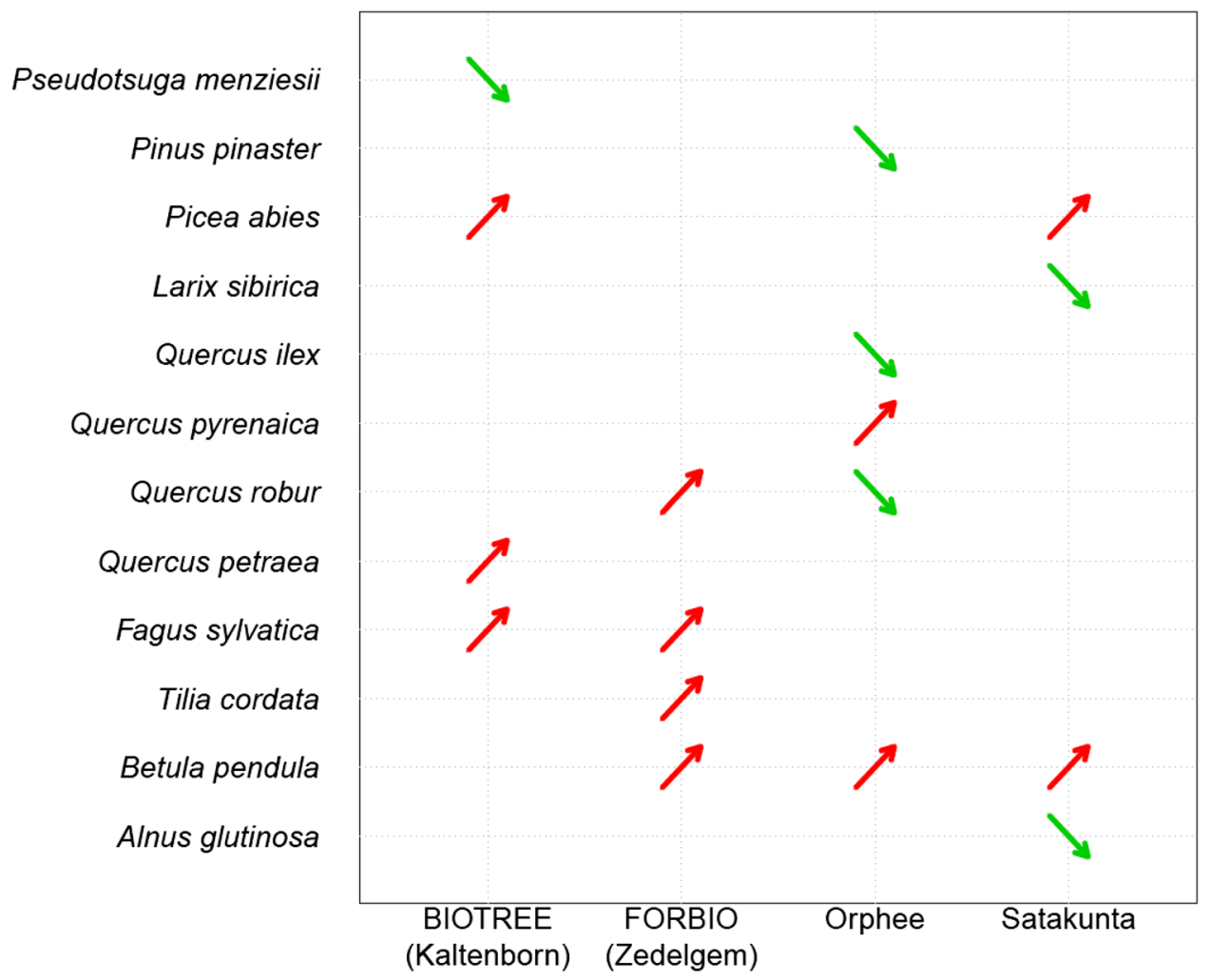

Fig. 5 Species-specific responses of defoliation (chewing + skeletonizing damage) to tree diversity in four TreeDivNet experiments. Green and red arrows indicate reduced and increased herbivory in mixed plots as compared to monocultures, i.e., associational resistance and associational susceptibility, respectively. It was estimated based on the site-specific difference in mean damage on a given species grown in mixtures and mean damage on corresponding monocultures. Data were taken from Setiawan et al. (2014) for the FORBIO experiment and from Haase et al. (2015) for the BIOTREE, ORPHEE, and Satakunta experiment 
species, such as conifers and broadleaves, can result in a more effective reduction in herbivore damage (Castagneyrol et al. 2014), but (2) a significant reduction in the proportion of host trees in mixtures is required to reduce damage by specialist herbivores (Jactel and Brockerhoff 2007).

\section{IDEAS FOR ADDITIONAL EXPERIMENTAL TREE DIVERSITY PLANTATIONS}

We are now entering the second decade of experimental manipulations of tree diversity. The TreeDivNet experiments have been designed to understand mechanisms and to quantify a large suite of ecosystem functions and services relevant to twenty-first century forest plantations. Gaps remain, however, in both the scale and scope of the existing experiments. We outline some important aspects here to guide future tree diversity experiments (see also Bruelheide et al. 2014).

First, while biodiversity research has made considerable advances on theoretical grounds, there is still a lack of linkages to applied sciences and industrial practices, even though it has been shown that different management types and intensities affect diversity-function relationships (e.g., Weigelt et al. 2009). In addition, the provision of wood is always listed among the ecosystem services a forest, planted or not, can provide. The outreach of next-generation experiments would be tremendously increased if practical issues were added already during the design phase, for example treatment testing and costing different planting patterns, maintenance methods, and harvesting techniques in a multi-species context, both in plantations and in naturally regenerated forests (see also Nichols et al. 2006). There is hence an important need for mixed species demonstration experiments, set-up in collaboration with forest managers and industries, and established at operational scales using available equipment and techniques. This could apply to both forestry and agroforestry systems, including short-rotation coppices and all variations of selection and multi-cohort stands. Moreover, to be practically relevant, future experiments may need to focus more strongly on testing or finding well-functioning genotypic and species compositions.

A second big issue in the design of tree diversity experiments is the scale, both temporal and spatial. Because of the high costs of large plots and the long-term time commitments, most plots in TreeDivNet experiments are, with a few exceptions, $1 / 4$ hectare or smaller (Table 1 ). Many processes affecting forest dynamics, e.g., competition and mortality, are scale dependent, and many of the forest ecosystem services, including the provision of timber, biodiversity, water purification, carbon storage, and recreational opportunities, are supplied at different spatial and temporal scales. Hence, there is an urgent need for tree diversity experiments that capture these larger-scale processes, similar to seminal watershed-level studies such as Hubbard Brook (www.hubbardbrook.org). Studies spanning multiple scales could provide pivotal information regarding the spatial and temporal scales at which forest biodiversity influences ecosystem functions and services. Comparing watersheds with different manipulated tree diversities would be a truly important step forward. Such large-scale experiments could be inspired by a land-sharing vs. land-sparing approach, such as the functional zoning in forestry (e.g., Messier et al. 2009). Furthermore, as effects of biodiversity on ecosystem functioning appear to be time dependent and to grow larger with time (Reich et al. 2012), longer-term studies are also required. While some of our experiments are planned with such long-term temporal perspective, others focus on early phases of establishment. Still missing are experiments where species are planted at different points in time, with pioneer and mid- to latesuccessional species, which without doubt would enhance our predictive capabilities of diversity effects along successional trajectories.

Third, theory and empirical evidence suggests that biodiversity is particularly important to buffer ecosystems against stressors and to increase their stability (Loreau and de Mazancourt 2013), but to date few TreeDivNet experiments explicitly incorporate stress as an experimental factor. The ORPHEE (France) and IDENT (Canada, Italy) experiments have incorporated a water availability treatment, and the IDENT site in Germany and Ridgefield (Australia) incorporate nutrient addition treatments, but the inclusion of other stressors would clearly broaden the inferences of TreeDivNet experiments. For example, results from smaller-scale experiments have shown that including factors such as mammalian herbivory (CookPatton et al. 2014) and fire (Adair et al. 2009) can influence the direction and magnitude of diversity effects.

Fourth and finally, although TreeDivNet includes experiments in tropical, temperate, and boreal systems, the distribution of experiments is skewed as relatively few are located in other important biomes/climate regions. For example, only two experiments lie in Central/South America and one in Africa, but these are not located in the largest forested areas and biodiversity hotspots on either continents (i.e., in the Amazon or Congo Basin). In addition, despite covering large areas on the globe, shrublands are also underrepresented.

The foresters of the nineteenth century demonstrated an impressive long-term perspective when they established the first forestry trials to find answers to the pressing questions of that time. Globally distributed experiments, such as TreeDivNet, could become new important research 
pillars to face the great challenges that global changes will put on forest ecosystems and to deliver highly relevant guidelines for forest policy and management worldwide. This is particularly important since plantations are likely to increase tremendously in area worldwide in the next decades.

Acknowledgments This paper is an outcome of a workshop kindly supported by sDiv, the Synthesis Centre of the German Centre for Integrative Biodiversity Research (iDiv) Halle-Jena-Leipzig (DFG FZT 118). The TreeDivNet experiments could not have been established without the help and support of many funding organizations and persons, too numerous to be listed here individually.

\section{REFERENCES}

Adair, E.C., P.B. Reich, S.E. Hobbie, and J.M.H. Knops. 2009. Interactive effects of time, $\mathrm{CO}_{2}, \mathrm{~N}$, and diversity on total belowground carbon allocation and ecosystem carbon storage in a grassland community. Ecosystems 12: 1037-1052.

Baeten, L., K. Verheyen, C. Wirth, H. Bruelheide, F. Bussotti, L. Finér, B. Jaroszewicz, F. Selvi, et al. 2013. A novel comparative research platform designed to determine the functional significance of tree species diversity in European forests. Perspectives in Plant Ecology, Evolution and Systematics 15: 281-291.

Bauhus, J., P. van der Meer, and M. Kanninen. 2010. Ecosystem goods and services from plantation forests. London: Earthscan.

Borer, E.T., W.S. Harpole, P.B. Adler, E.M. Lind, J.L. Orrock, E.W. Seabloom, and M.D. Smith. 2014. Finding generality in ecology: A model for globally distributed experiments. Methods in Ecology and Evolution 5: 65-73.

Bruelheide, H., K. Nadrowski, T. Assmann, J. Bauhus, S. Both, F. Buscot, X.-Y. Chen, B. Ding, et al. 2014. Designing forest biodiversity experiments: General considerations illustrated by a new large experiment in subtropical China. Methods in Ecology and Evolution 5: 74-89.

Cardinale, B.J., J.E. Duffy, A. Gonzalez, D.U. Hooper, C. Perrings, P. Venail, A. Narwani, G.M. Mace, et al. 2012. Biodiversity loss and its impact on humanity. Nature 486: 59-67.

Carnol, M., L. Baeten, E. Branquart, J.C. Grégoire, A. Heughebaert, B. Muys, Q. Ponette, and K. Verheyen. 2014. Ecosystem services of mixed species forest stands and monocultures: Comparing practitioners' and scientists' perceptions with formal scientific knowledge. Forestry 87: 639-653.

Castagneyrol, B., B. Giffard, C. Péré, and H. Jactel. 2013. Plant apparency, an overlooked driver of associational resistance to insect herbivory. Journal of Ecology 101: 418-429.

Castagneyrol, B., H. Jactel, C. Vacher, E.G. Brockerhoff, and J. Koricheva. 2014. Effects of plant phylogenetic diversity on herbivory depend on herbivore specialization. Journal of Applied Ecology 51: 134-141.

Cerbu, G.A., B.M. Swallow, and D.Y. Thompson. 2011. Locating REDD: A global survey and analysis of REDD readiness and demonstration activities. Environmental Science \& Policy 14: 168-180.

Chave, J., C. Andalo, S. Brown, M.A. Cairns, J.Q. Chambers, D. Aemus, H. Fölster, F. Fromard, et al. 2005. Tree allometry and improved estimation of carbon stocks and balance in tropical forests. Oecologia 145: 87-99.

Cook-Patton, S.C., M. LaForgia, and J.D. Parker. 2014. Positive interactions between herbivores and plant diversity shape forest regeneration. Proceedings of the Royal Society B: Biological Sciences 281: 20140261.

FAO. 2006. Global forest resources assessment 2005, progress towards sustainable forest management. FAO Forestry Paper 147, Food and Agriculture Organization of the United Nations, Rome, Italy.

FAO. 2010. Global Forest Resources Assessment 2010. FAO Forestry Paper 163, Food and Agriculture Organization of the United Nations, Rome, Italy.

Haase, J., B. Castagneyrol, J.H.C. Cornelissen, J. Ghazoul, J. Kattge, J. Koricheva, M. Scherer-Lorenzen, S. Morath, et al. 2015. Contrasting effects of tree diversity on young tree growth and resistance to insect herbivores across three biodiversity experiments. Oikos. doi:10.1111/oik.02090.

Hanewinkel, M., D.A. Cullmann, M.J. Schelhaas, G.J. Nabuurs, and N.E. Zimmermann. 2012. Climate change may cause severe loss in the economic value of European forest land. Nature Climate Change 3: 203-207.

Hector, A., C. Philipson, P. Saner, J. Champagne, D. Dzulkifli, M. O'Brien, J.L. Snaddon, P. Ulok, et al. 2011. The Sabah Biodiversity Experiment: A long-term test of the role of tree diversity in restoring tropical forest structure and functioning. Philosophical Transactions of the Royal Society B 366: 3303-3315.

Hulvey, K.B., R.J. Hobbs, R.J. Standish, D.B. Lindenmayer, L. Lach, and M.P. Perring. 2013. Benefits of tree-mixes in carbon plantings. Nature Climate Change 3: 869-874.

Jactel, H., and E.G. Brockerhoff. 2007. Tree diversity reduces herbivory by forest insects. Ecology Letters 10: 835-848.

Jactel, H., J. Petit, M.L. Desprez-Lousteau, S. Delzon, D. Piou, A. Battisti, and J. Koricheva. 2012. Drought effects on damage by forest insects and pathogens: A meta-analysis. Global Change Biology 18: 267-276.

Kanninen, M. 2010. Plantation forests: Global perspectives. In Ecosystem goods and services from plantation forests, ed. J. Bauhus, P. van der Meer, and M. Kanninen, 1-15. London: Earthscan.

Loreau, M., and C. de Mazancourt. 2013. Biodiversity and ecosystem stability: A synthesis of underlying mechanisms. Ecology Letters 16: 106-115.

Messier, C., R. Tittler, D.D. Kneeshaw, N. Gélinas, A. Paquette, K. Berninger, H. Rheault, P. Meek, et al. 2009. TRIAD zoning in Quebec: Experiences and results after 5 years. Forestry Chronicle 85: 885-896.

Morgenstern, E.K. 2007. The origin and early application of the principle of sustainable forest management. Forestry Chronicle 83: 485-489.

Morin, X., L. Fahse, M. Scherer-Lorenzen, and H. Bugmann. 2011. Tree species richness promotes productivity in temperate forests through strong complementarity between species. Ecology Letters 14: 1211-1219.

Nadrowski, K., C. Wirth, and M. Scherer-Lorenzen. 2010. Is forest diversity driving ecosystem function and service? Current Opinion in Environmental Sustainability 2: 75-79.

Nichols, J.D., M. Bristow, and J.K. Vanclay. 2006. Mixed-species plantations: Prospects and challenges. Forest Ecology and Management 233: 383-390.

Olson, D.M., E. Dinerstein, E.D. Wikramanayake, N.D. Burgess, G.V.N. Powell, E.C. Underwood, J.A. D'Amico, I. Itoua, et al. 2001. Terrestrial ecoregions of the world: A new map of life on Earth. BioScience 51: 933-938.

Paquette, A., and C. Messier. 2010. The role of plantations in managing the world's forests in the Anthropocene. Frontiers in Ecology and the Environment 8: 27-34.

Paquette, A., and C. Messier. 2013. Managing tree plantations as complex adaptive systems. In Managing forests as complex 
adaptive systems: Building resilience to the challenge of global change, ed. C. Messier, K. Puettmann, and K.D. Coates, 299-326. New York: Earthscan.

Pawson, S.M., A. Brin, and E.G. Brockeroff. 2013. Plantation forests, climate change and biodiversity. Biodiversity and Conservation 22: 1203-1227.

Pedlar, J.H., D.W. McKenney, I. Aubin, T. Beardmore, J. Beaulieu, L. Iverson, G.A. O'Neill, R.S. Winder, et al. 2012. Placing forestry in the assisted migration debate. BioScience 62: 835-842.

Péladeau, N. 2003. WordStat content analysis module for SIMSTAT. Montréal: Provalis Research.

Perring, M.P., R.J. Standish, K.B. Hulvey, L. Lach, T.K. Morald, R. Parsons, R.K. Didham, and R.J. Hobbs. 2012. The Ridgefield Multiple Ecosystem Services Experiment: Can restoration of former agricultural land achieve multiple outcomes? Agriculture, Ecosystems \& Environment 163: 14-27.

Potvin, C., and N. Gotelli. 2008. Biodiversity enhances individual performance but does not affect survivorship in tropical trees. Ecology Letters 11: 217-223.

Reich, P.B., D. Tilman, F. Isbell, K. Mueller, S.E. Hobbie, D.F.B. Flynn, and N. Eisenhauer. 2012. Impacts of biodiversity loss escalate through time as redundancy fades. Science 336: 589-592.

Riihimaki, J., P. Kaitaniemi, J. Koricheva, and H. Vehviläinen. 2005. Testing the enemies hypothesis in forest stands: The important role of tree species composition. Oecologia 142: 90-97.

Sapijanskas, J., C. Potvin, and M. Loreau. 2013. Beyond shading: Litter production by neighbors contributes to over yielding in tropical trees. Ecology 94: 941-952.

Scherer-Lorenzen, M. 2014. The functional role of biodiversity in the context of global change. In Forests and global change, ed. D. Burslem, D. Coomes, and W. Simonson, 195-238. Cambridge: Cambridge University Press.

Scherer-Lorenzen, M., E.D. Schulze, A. Don, J. Schumacher, and E. Weller. 2007. Exploring the functional significance of forest diversity: A new long-term experiment with temperate tree species (BIOTREE). Perspectives in Plant Ecology, Evolution and Systematics 9: 53-70.

Setiawan, N.N., M. Vanhellemont, L. Baeten, M. Dillen, and K. Verheyen. 2014. The effects of local neighbourhood diversity on pest and disease damage of trees in a young experimental forest. Forest Ecology and Management 334: 1-9.

Smith, A.R., M. Lukac, R. Hood, J.R. Healey, F. Miglietta, and D.L. Godbold. 2013. Elevated $\mathrm{CO}_{2}$ enrichment induces a differential biomass response in a mixed species temperate forest plantation. New Phytologist 198: 156-168.

Stegen, J.C., N.G. Swenson, R. Valencia, B.J. Enquist, and J. Thompson. 2009. Above-ground forest biomass is not consistently related to wood density in tropical forests. Global Ecology and Biogeography 18: 617-625.

Thomas, S., P. Dargusch, S. Harrison, and J. Herbohn. 2010. Why are there so few afforestation and reforestation Clean Development Mechanism projects? Land Use Policy 27: 880-887.

Tobner, C.M., A. Paquette, P.B. Reich, D. Gravel, and C. Messier. 2014. Advancing biodiversity-Ecosystem functioning science with the use of high-density tree-based experiments. Oecologia 174: 609-621.

van Hensbergen, H.J. 2006. Plantaciones, sustentabilidad y certificación. Revista Ambiente y Desarollo 22: 21-28. (in Spanish).

Verheyen, K., K. Ceunen, E. Ampoorter, L. Baeten, B. Bosman, E. Branquart, M. Carnol, H. De Wandeler, J.C. Grégoire, et al. 2013. Assessment of the functional role of tree diversity: The multi-site FORBIO experiment. Plant Ecology and Evolution 146: 26-35.

Weigelt, A., W.W. Weisser, N. Buchmann, and M. Scherer-Lorenzen. 2009. Biodiversity for multifunctional grasslands: Equal productivity in high-diversity low-input and low-diversity high-input systems. Biogeosciences 6: 1695-1706.

Woods, A., K.D. Coates, and A. Hamann. 2005. Is an unprecedented dothistroma needle blight epidemic related to climate change? BioScience 55: 761-769.

Ziania, D., P. Muukkonen, R. Mäkipää, and M. Mencuccini. 2005. Biomass and stem volume equations for tree species in Europe. Silva Fennica Monographs 4. Tammer-Paino Oy, Tampere, Finland.

\section{AUTHOR BIOGRAPHIES}

Kris Verheyen $(\varangle)$ is an Associate Professor at the Department of Forest and Water Management, Ghent University. His research interests include studies on (1) the link between biodiversity and ecosystem functioning and (2) the impact of global changes on biodiversity and ecosystem functioning. Using these insights, he tries to develop (3) guidelines for ecological restoration and (4) management strategies for the optimal delivery of multiple ecosystem services. Address: Forest \& Nature Lab, Department of Forest and Water Management, Ghent University, Geraardsbergsesteenweg 267, 9090 Melle-Gontrode, Belgium.

e-mail: kris.verheyen@ugent.be

Margot Vanhellemont is a Postdoctoral Researcher at the Department of Forest and Water Management, Ghent University. Her research interests include forest dynamics and tree growth.

Address: Forest \& Nature Lab, Department of Forest and Water Management, Ghent University, Geraardsbergsesteenweg 267, 9090 Melle-Gontrode, Belgium.

e-mail: margot.vanhellemont@ugent.be

Harald Auge is a Senior Scientist at the Helmholtz Centre for Environmental Research - UFZ and the German Centre for Integrative Biodiversity Research (iDiv) Halle-Jena-Leipzig, Germany. His research interests include plant population and community ecology, plant-herbivore interactions, and biological invasions.

Address: Department of Community Ecology, Helmholtz Centre for Environmental Research, Theodor-Lieser-Straße 4, 06120 Halle, Germany.

Address: German Centre for Integrative Biodiversity Research (HalleJena-Leipzig), iDiv, Deutscher Platz 5e, 04103 Leipzig, Germany. e-mail: harald.auge@ufz.de

Lander Baeten is an Assistant Professor at the Department of Forest and Water Management, Ghent University. He is interested in biodiversity conservation and restoration, the functional importance of species and quantitative ecology.

Address: Forest \& Nature Lab, Department of Forest and Water Management, Ghent University, Geraardsbergsesteenweg 267, 9090 Melle-Gontrode, Belgium.

e-mail: lander.baeten@ugent.be

Christopher Baraloto is currently the Director of the International Center for Tropical Botany in the Department of Biological Sciences at Florida International University, Research Director with the mixed research unit in Tropical Forest Ecology (UMR EcoFoG) in Kourou, French Guiana, and affiliate Professor in the Department of Botany at the Instituto Nacional de Pesquisas da Amazônia. His research focuses on tropical botany, community ecology, and conservation. $\mathrm{He}$ works in sites across the Amazon and Guiana Shield seeking to understand the factors controlling plant species distributions, and the impacts of global change on forest structure and biodiversity. Address: Department of Biological Sciences, International Center for Tropical Botany, Florida International University, 11200 SW 8th Street, OE 167, Miami, FL 33199, USA. 
Address: INRA, UMR Ecologie des Forêts de Guyane, 97310 Kourou, French Guiana.

Address: Department of Botany, Instituto Nacional de Pesquisas da Amazônia, Manaus, Brazil.

e-mail: chris.baraloto@ecofog.gf

Nadia Barsoum is a forest ecologist at Forest Research, UK. Her research interests include understanding the influence of a diversification of forest stands on biodiversity and woodland ecosystem resilience and developing guidance on best forestry practice to protect and enhance woodland biodiversity.

Address: Centre for Ecosystems, Society and Biosecurity, Forest Research, Alice Holt Lodge, Farnham GU10 4LH, Surrey, UK.

e-mail: nadia.barsoum@forestry.gsi.gov.uk

Simon Bilodeau-Gauthier is a Postdoctoral Researcher at the Centre for Forest Research, Université du Québec à Montréal (UQAM), Canada. $\mathrm{He}$ is a forest ecologist whose research interests include biodiversity, silviculture, plant-soil interactions, plant nutrition, and soil fertility. He was previously a postdoc at the German Centre for Integrative Biodiversity Research (iDiv) in Leipzig, where he worked on TreeDivNet data.

Address: Centre for Forest Research (CFR), Université du Québec à Montréal (UQM), P.O. Box 8888, Centre-ville Station, Montréal, QC H3C 3P8, Canada.

e-mail: simonbgauthier@yahoo.ca

Helge Bruelheide is Professor of Geobotany at the Institute of Biology at Martin Luther University Halle-Wittenberg and one of the directors of the German Centre for Integrative Biodiversity Research (iDiv) Halle-Jena-Leipzig. He is a trained vegetation ecologist with a focus on community ecology, biodiversity effects, and ecosystem functioning. In TreeDivNet he is coordinating the BEF-China experiment in Jiangxi, China.

Address: Institute of Biology/Geobotany and Botanical Garden, Martin Luther University Halle Wittenberg, Am Kirchtor 1, 06108 Halle, Germany.

e-mail: helge.bruelheide@botanik.uni-halle.de

Bastien Castagneyrol is a Junior Scientist at the French National Institute of Agricultural Research (INRA). He is interested in plant-herbivore interactions and the effect of plant diversity on insect herbivory.

Address: INRA, UMR 1202 BIOGECO, 69 route d'Arcachon, 33612 Cestas, France.

Address: INRA, UMR 1202 BIOGECO, 33610 Cestas, France.

Address: UMR 1202, BIOGECO, University of Bordeaux, 33615 Pessac, France.

e-mail: bastien.castagneyrol@pierroton.inra.fr

Douglas Godbold is a Professor at the Institute of Forest Ecology, Universität für Bodenkultur (BOKU). His research interests include tree and belowground biodiversity in relation to ecosystem function, and the effects of climate change on forests.

Address: Institute of Forest Ecology, Universität für Bodenkultur (BOKU), Peter Jordan Str 82, 1190 Vienna, Austria.

e-mail: douglas.godbold@boku.ac.at

Josephine Haase is a Postdoctoral Researcher at the University of Zurich, Institute of Evolutionary Biology and Environmental Studies. Her research interests are to understand the functional linkages between species and trophic levels, their interactions with the environment, and how these processes determine large-scale ecological patterns.

Address: Institute of Evolutionary Biology and Environmental Studies, University of Zurich, Winterthurerstrasse 190, 8057 Zurich, Austria.

Address: Faculty of Biology, University of Freiburg, Schaenzlestrasse 1, 79104 Freiburg, Germany.
Address: Ecosystem Management, Department of Environmental Systems Science, ETH Zurich, Universitaetsstr. 16, 8092 Zurich, Switzerland. e-mail: josephine.haase@biologie.uni-freiburg.de

Andy Hector is Professor of ecology in the University of Oxford, Department of Plant Sciences. He is a plant community ecologist interested in how biodiversity is maintained or lost and in the consequences for ecosystem functioning and stability. $\mathrm{He}$ is also the scientific PI on the Sabah Biodiversity Experiment (www. sabahbiodiversityexperiment.org) and recently published The new statistics with R: An introduction for biologists.

Address: Department of Plant Sciences, University of Oxford, South Parks Road, Oxford OX1 3RB, UK.

e-mail: andrew.hector@plants.ox.ac.uk

Hervé Jactel is a Senior Scientist at the National Institute of Agricultural Research (INRA, France). His research interests include forest entomology and ecology, and more particularly the relationships between forest diversity and resistance to insect herbivores.

Address: INRA, UMR 1202 BIOGECO, 33610 Cestas, France.

Address: UMR 1202, BIOGECO, University of Bordeaux, 33615 Pessac, France.

e-mail: herve.jactel@pierroton.inra.fr

Julia Koricheva is a Professor of Ecology at Royal Holloway University of London. Her research interests include plant-herbivore interactions, forest diversity and ecosystem function, and research synthesis in ecology.

Address: School of Biological Sciences, Royal Holloway University of London, Egham TW20 0EX, Surrey, UK.

e-mail: julia.koricheva@rhul.ac.uk

Michel Loreau is Research Director at the Experimental Ecology Station of the National Centre for Scientific Research (CNRS, France). His research goal is to build the theoretical foundations of a new ecological synthesis that integrates the divergent perspectives of community ecology, evolutionary ecology, and ecosystem ecology. His main research theme during the past 20 years has been the relationship between biodiversity and ecosystem functioning and the ecological and societal consequences of biodiversity loss.

Address: Centre for Biodiversity Theory and Modelling, Station d'Ecologie Expérimentale du CNRS, 2 route du CNRS, 09200 Moulis, France.

e-mail: michel.loreau@ecoex-moulis.cnrs.fr

Simone Mereu is a Postdoctoral Researcher at the University of Sassari. His research interests include terrestrial carbon and water cycles, plant and community responses to drought, diversity effects with a special focus on Mediterranean communities.

Address: Department of Science for Nature and Natural Resources, University of Sassari, Via Enrico De Nicola 1, 07100 Sassari, Italy. Address: Euro-Mediterranean Center on Climate Change (CMCC), Impacts on Agriculture, Forest, and Natural Ecosystems, Lecce, Italy. e-mail: simonemereu@uniss.it

Christian Messier is Professor of Forest Ecology at the University of Québec in Montréal (UQAM) and in Outaouais (UQO). His research interests include the development of sustainable tree and forest management practices in both urban and natural forests.

Address: Centre for Forest Research (CFR), Université du Québec à Montréal (UQM), P.O. Box 8888, Centre-ville Station, Montréal, QC H3C 3P8, Canada.

Address: Institut des Sciences de la Forêt tempérée (ISFORT), Université du Québec en Outaouais (UQO), 8, Rue Principale, Ripon, QC JOV 1V0, Canada.

e-mail: messier.christian@uqam.ca 
Bart Muys is a Professor of Forest Ecology and Management at the University of Leuven. His research contributes to evaluation and optimization of forest management for multiple ecosystem services under a changing environment. He has an interest in the relation between forest biodiversity function and provisioning and regulating services including carbon sequestration and green and blue waterrelated services.

Address: Division Forest, Nature and Landscape, Department of Earth \& Environmental Sciences, KU Leuven, Celestijnenlaan 200E, Box 2411, 3001 Louvain, Belgium.

e-mail: bart.muys@ees.kuleuven.be

Philippe Nolet is a Professor at the Department of Natural Resources, Université du Québec en Outaouais. His research interests include studies on (1) silviculture and applied ecology, (2) the impact and benefits of silviculture on forest ecosystems in the context of global changes, and (3) the development of silvicultural approaches to favour forest ecosystem resilience.

Address: Département des Sciences naturelles, Université du Québec en Outaouais, 58 Principale, Ripon, QC J0V 1V0, Canada.

e-mail: philippe.nole@uqo.ca

Alain Paquette is a Research Associate at the Centre for Forest Research, Université du Québec à Montréal. He is interested in biodiversity and ecosystem functioning in trees and coordinates the IDENT network of biodiversity experiments.

Address: Centre for Forest Research (CFR), Université du Québec à Montréal (UQM), P.O. Box 8888, Centre-ville Station, Montréal, QC H3C 3P8, Canada.

e-mail: alain.paquette@gmail.com

John Parker is a Senior Scientist at the Smithsonian Environmental Research Center. His research interests include (1) impacts of herbivores on plant community structure and (2) plant invasions, (3) effects of biodiversity on populations, communities, and ecosystems, (4) effects of climate change on plant populations and plant-herbivore interactions, and (5) chemical ecology of plant-herbivore interactions.

Address: Smithsonian Environmental Research Center, 647 Contees Wharf Road, Edgewater, MD 21037, USA.

e-mail: parkerj@si.edu

Mike Perring is a Postdoctoral Researcher at Ghent University and The University of Western Australia. His research interests include restoration ecology and the influence of species composition on ecosystem function in an era of environmental change.

Address: Forest \& Nature Lab, Department of Forest and Water Management, Ghent University, Geraardsbergsesteenweg 267, 9090 Melle-Gontrode, Belgium.

Address: Ecosystem Restoration and Intervention Ecology Research Group, School of Plant Biology, The University of Western Australia, 35 Stirling Highway, Crawley, WA 6009, Australia.

e-mail: michael.perring@uwa.edu.au

Quentin Ponette is Professor at the Université Catholique de Louvain, Earth and Life Institute. His research interests include biogeochemistry of forest ecosystems and functional biodiversity.
Address: Earth and Life Institute - Environmental Sciences, Université Catholique de Louvain (UCL), Croix du Sud 2, Box L7.05.09, 1348 Louvain-la-Neuve, Belgium.

e-mail: quentin.ponette@uclouvain.be

Catherine Potvin is a Professor at McGill University in Montreal, Canada. Her research focusses on the link between tree diversity and carbon cycling in tropical landscapes.

Address: Department of Biology, McGill University, 1205 Dr Penfield, Montréal, QC H3A-1B1, Canada.

Address: Smithsonian Tropical Research Institute, Panama, USA.

e-mail: catherine.potvin@mcgill.ca

Peter Reich is a Professor at the University of Minnesota, with a joint affiliation at the University of Western Sydney. His research interests include impacts of global environmental change (e.g., biodiversity loss, climate warming, rising $\mathrm{CO} 2$ ) on terrestrial ecosystems, and the feedbacks of such responses to the carbon cycle and climate system. Address: Department of Forest Resources, University of Minnesota, 1530 Cleveland Avenue North, St Paul, MN 55108, USA.

Address: Hawkesbury Institute for the Environment, University of Western Sydney, Penrith, NSW 2753, Australia.

e-mail: preich@umn.edu

Andy Smith is Director of Research and Lecturer in Forestry at the School of Environment, Natural Resources and Geography, Bangor University. He is also a visiting scientist at NERC's Centre for Ecology and Hydrology, Bangor and forestry programme leader at the joint Bangor-CSUFT University Campus, Changsha, China. His research area is forest ecology, forest biogeochemistry, and control of GHG emissions. He has expertise in climate change impacts on biogeochemical processes and plant-soil interactions. His work includes studies on the impact of drought, warming and elevated $\mathrm{CO} 2$ on plant community dynamics, and belowground ecosystem processes.

Address: School of Environment, Natural Resources and Geography, Bangor University, Thoday Building, Bangor LL57 2UW, Gwynedd, UK.

e-mail: a.r.smith@bangor.ac.uk

Martin Weih is a Professor at the Swedish University of Agricultural Sciences. His research interests include the ecology and ecophysiology of forest trees and agricultural crops.

Address: Department of Crop Production Ecology, Swedish University of Agricultural Sciences, PO Box 7043, 75007 Uppsala, Sweden. e-mail: martin.weih@slu.se

Michael Scherer-Lorenzen is a Professor for Geobotany at the Faculty of Biology, University of Freiburg. His research interest is on the relationship between biodiversity and ecosystem functioning, and on the underlying mechanisms. This work focuses on biogeochemical processes related to carbon and nutrient dynamics (e.g., productivity, litter decomposition, nitrogen retention), and is done in grassland and forest ecosystems.

Address: Faculty of Biology, University of Freiburg, Schaenzlestrasse 1, 79104 Freiburg, Germany.

e-mail: michael.scherer@biologie.uni-freiburg.de 